\title{
Service Quality in Sport: A Higher Education Perspective
}

\author{
*Dayaneethie Veerasamy, Jeevarathnam Parthasarathy Govender, Magalingam Atheeshey Pillay \\ Durban University of Technology, South Africa \\ *veerasamyd@dut.ac.za
}

\begin{abstract}
Although the University remains a strong competitor in major sport codes, there has been a general decline in student participation in physical activity. This is evident by the low participation rate of students in competitive sport. The aim of this paper was to investigate students' expectations and perceptions of the sport offering at the University. A total of 400 students completed the survey using a questionnaire developed from the SERVQUAL instrument. All the service quality dimensions in the students' surveys of sport at the University contain negative mean gap scores. From these findings, the Sport department at the University can identify specific gaps in the service quality dimensions and seek to close them. Service quality dimensions that are deemed to be good predictors of service quality have been related to factors relating to tangibility, reliability and responsiveness. The University should address these dimensions in its attempt to improve on service quality. The reliability dimension, which has emerged as the most important service quality predictor, needs the most attention.
\end{abstract}

Key words: Expectations, perceptions, service quality, tangibility, reliability, responsiveness

\section{Introduction}

Sport at universities is critical as it plays an integral and important role in student life. It builds team spirit, camaraderie and plays a role in cementing relationships. It also encourages healthy competition, promotes discipline and fosters a gracious attitude to both winning and losing. Lessons learnt through participation in sport are valuable to all areas of life (Sport Union-UKZN, 2006). According to Lagrosen \& Lagrosen (2007), the sport and fitness industry has received little research attention from a service quality perspective. Knowledge of service quality assessments made by students of the sport organization at the Durban University of Technology (DUT) will enable managers to track students' perceptions over time and to direct resources in areas which are important to them. If an organization does not do market research on the topic of market expectations and perceptions, it may fail in fulfilling customer requirements (Zeithaml, Bitner \& Gremler, 2006). University sport has been at the fore-front of university life for many decades. With the advent of competitive student sport, many students have progressed up the development continuum at club and provincial level to become national competitors. Although the DUT remains a strong competitor in major sport codes, there is a general decline in student physical activity, as evidenced by: low participation rate by students in competitive sport; the number of sport codes reduced from twenty four in 2000 to fourteen in 2008; and low usage of facilities for recreational purposes. The DUT had a proud record of achievement both in the provincial leagues and at national student tournaments. However, by comparison, other leading universities of technologies [UOTs] and the state of the sport facilities on offer, the DUT lags behind in student participation levels and facilities. The objective of this study was to investigate students' expectations and perceptions of the sport offering. Mainly, this study seeks to identify gaps between the expectations and perceptions of the sport offering at DUT. Although the study concentrates on one university in South Africa, the findings are significant to other universities, especially those in developing countries.

\section{Review of literature}

Customer expectations and perceptions of service: According to Ryningen (2010), customer-centrism is the very core of an organization and it is important that sport managers better understand how a marketing perspective can assist them to operate effectively within the market environment. Good service provision does not necessarily mean "doing everything the customer wants" as much as bringing the expectations of the service provider and the customer closely in line. Customer expectations serve as a benchmark against which present and future service encounters are compared. It is what customers think they will receive in the service encounter (Cant, Brink \&-Brijball, 2002). This is expanded further by Kotler \& Armstrong (2008), who believe that, for ultimate customer satisfaction, today's marketers must be good at creating customer value and managing customer relationships. Marketers must attract 
customers with strong value propositions, which are critical to the success of every organization. In markets where current and prospective students are regarded as the target market and 'final consumer' of the service offering, several important actions can be taken into account by Higher Education Institutions (HEIs) (Melewar \& Akel, 2005). Firstly, HEIs have to implement strategies to satisfy customer expectations and enhance their competitiveness. Secondly, effective communication strategies need to be employed to convey the unique selling propositions (USPs) of the institution. Finally, these USPs must be communicated to all relevant stakeholders. Zeithaml et al. (2006) state that expectations are beliefs about service delivery that serves as standards against which performance is judged. Customer expectations are critical to service marketers and will deeply influence customer behavior. These authors further mention that customer expectations are not stable and are human perceptions based on verbal information, personal needs, experience and commercial information

Perceptions are frequently developed over a period of time and reflect the ways that one has been treated and his/her values, priorities, prejudices, and sensitivity to others (Harris, 2006). The customer service provider should anticipate customer resistance based on the customers' prior interaction and work at providing the customers with excellent service so that their current perception is a positive one. Customers may not remember every detail of an experience, but, if left with a positive feeling in combination with other experiences, their perception of the organization will be retained (Armstrong \&Keller, 2006). According to Bodet (2006), service consumption in gymnasiums is a process that implies an interaction between the gymnasium and a member. Consequently, the members' perceptions of interaction with employees or managers will affect the members' perception of the gymnasium. The study found that staff appears to be a key element in the service encounter and their capacity to answer or solve problems encountered by the member on the premises. According to Cant et al. (2002), perception is the process by which people select, organize and interpret stimuli to the five senses of sight, sound, smell, touch and taste; in other words, it is the way that buyers interpret or give meaning to the world surrounding them. Therefore, the understanding of perception is an essential guide to marketing. The customer's perception of service quality has attracted quite extensive attention from researchers and practitioners. Zeithaml \& Bitner (2000) describe customer perceptions as: "the subjective assessments of actual service experiences". This refers to how customers perceive services: how they assess the quality of received service; whether they are satisfied; and whether they have received good value. Therefore, customer expectations of service are also defined as customer perceptions of quality, satisfaction and value. In short, the customers' perceptions are the way that people see something based on their experience. Everyone's perception of a situation will be at least slightly different.

\section{The dimensions of service quality}

Tangibility: Tangibles relates to 'the appearance of facilities, equipment, personnel, and communication materials' (Bateson and Hoffman, 2011). Since the tangible and visual elements will be critical to efficiency as well as to overall perceptions of the firm and the brand, service companies are likely to use tangibles to enhance their image and convey quality service to customers. Most companies also combine tangibles with another dimension to create a service quality strategy for the firm.

Reliability: Lovelock and Wirtz (2011) define reliability as the ability to perform dependably, accurately and consistently. Reliability is also about performing the service right the first time. This component has been found to be the most important to customers.

Responsiveness: Responsiveness reflects a service firm's commitment to provide its services in a timely manner. As such, the responsiveness dimension concerns the willingness and/ readiness of employees to provide a service (Bateson and Hoffman, 2011).

\section{Methodology}

The purpose of the study was to examine the different dimensions of service quality and then identify the critical elements of service quality in the current service offering at the DUT. The research, therefore, employed a descriptive study to investigate what factors influenced the service quality in the DUT

Sample: Two types of non-probability sampling were employed. Firstly, quota sampling was used to seek respondents in the same proportions. This method is regarded as the most useful form of non-random sampling and does offer a cost and time-effective solution for questionnaire-based research by the market 
research industry (Curwin \& Slater, 2002). The sample comprised 400 students in terms of the predicted population of 21000 students studying at the Durban University of Technology (DUT). The breakdown of the quota was calculated using the mean proportion percentage across the faculties of the DUT. Secondly, convenience sampling, as the cheapest and easiest to conduct for the sample, was used to select respondents

Instrument and procedure: The data was gathered by administering a questionnaire to students across six campuses of the DUT. The SERVQUAL instrument was used to measure students' expectations and perceptions of service quality of the DUT sport offering. It is a pre-existing, validated instrument by virtue of its extensive use in a variety of service quality settings. The SERVQUAL model consists of a standardized questionnaire which includes two statements for each of the 13 items that represent the three dimensions described. An expectations' section containing 13 statements is used to ascertain the general expectations of customers concerning a service. A perceptions' section containing a matching set of 13 statements is used to measure customers' assessments of a specific firm within the service category (Perez, Abad, Carrillo \& Fernandez, 2007: 140-141). Five of the 13 statements are used to measure reliability, four to measure responsiveness and four to measure tangibles (see Table 2.2). Statements in both sections use a five-point Likert scale ranging from "Strongly Agree" (5) to "Strongly Disagree" (1) (Curry and Sinclair, 2002: 200). According to Leedy and Ormrod, (2005: 29), reliability can be seen as the consistency of performance of the measuring instrument. This means that, apart from delivering accurate results, the measuring instrument must deliver similar results consistently.

Data analysis: The collected data was analyzed by using the Statistical Package for Social Sciences (SPSS) version 14.0 for Windows. A descriptive analysis of the biographical data (age, gender, race, year of study of respondents and location in terms of residence) was done. The reliability of the scale was measured using Cronbach alpha.

\section{Results and Discussion}

Table 1: Biographical Data of Respondents

\begin{tabular}{ll}
\hline TOTAL NUMBER OF STUDENTS $=\mathbf{4 0 0}$ & PERCENTAGE (\%) \\
\hline Age: $18-20$ & $49(196)$ \\
$21-23$ & $44,5(178)$ \\
24 and older & $6,5(26)$ \\
Gender: Male & $43(173)$ \\
Female & $57(227)$ \\
Race: Black & $43(173)$ \\
White & $30(120)$ \\
Asian & $15(60)$ \\
Colored & $12(47)$ \\
Year of Study: First & $41(163)$ \\
Second & $36(145)$ \\
Third & $23(92)$ \\
Location: Residence & $17(70)$ \\
Non-residence & $83(330)$ \\
\hline
\end{tabular}

As depicted in Table 1, 49\% (196) of the respondents were in the 18-20 age group, followed by $44.5 \%$ (178) in the $21-23$ age group and $6.5 \%$ (26) of the respondents were 24 years and older. The age profile indicates that the 18 to 20 age group was the dominant group. The percentage of male respondents was $43.3 \%$ (173), while the percentage of female respondents was $56.7 \%$ (227). $43.3 \%$ (173) of the respondents were African, followed by 30\% (120) Asian, 15\% (60) White and 11.8\% (47) Colored. 40.8\% (163) of the respondents were in their first year of study, followed by 36.3\% (145) in their second year and $23 \%$ (92) in the third year of study. First year students were the dominant group. The percentage of respondents residing in DUT residence was 17\% (70), while 83\% (330) were non-resident respondents.

Dimensions: This tangibles dimension is related to physical facilities, equipment, materials, and appearance of the service environment. As presented in Figure 1, the expectation mean score of 3.78 is attributed to "materials are visually appealing", while "physical facilities is visually appealing" and "personnel are neat in appearance" for expectation achieved similar mean scores of 3.75 and 3.74 respectively. The lowest mean score of 3.51 was for "modern looking equipment". It is evident that the 
mean score of 2.55 relating to perception for "modern looking equipment" is the lowest. The largest mean score of 3.03 was for "materials are visually appealing". A comparison of the mean expectation and perception indicated a large difference between the dimensions. The largest gap 1.12 was found in service quality statement "physical facilities are visually appealing". The smallest gap 0.75 was for "materials are visually appealing". The latter was indicative of the importance of information that is presented in an attractive manner. With the exception of question 4 relating to "materials are visually appealing", the other showed a large gap. Since the tangible and visual elements of the site will be critical to efficiency as well as to overall perceptions of the firm and the brand, service companies are likely to use tangibles to enhance their image and convey quality service to customer. Most companies also combine tangibles with another dimension to create a service quality strategy for the firm (Zeithaml et al., 2006).

\section{Figure 1: Tangibles}

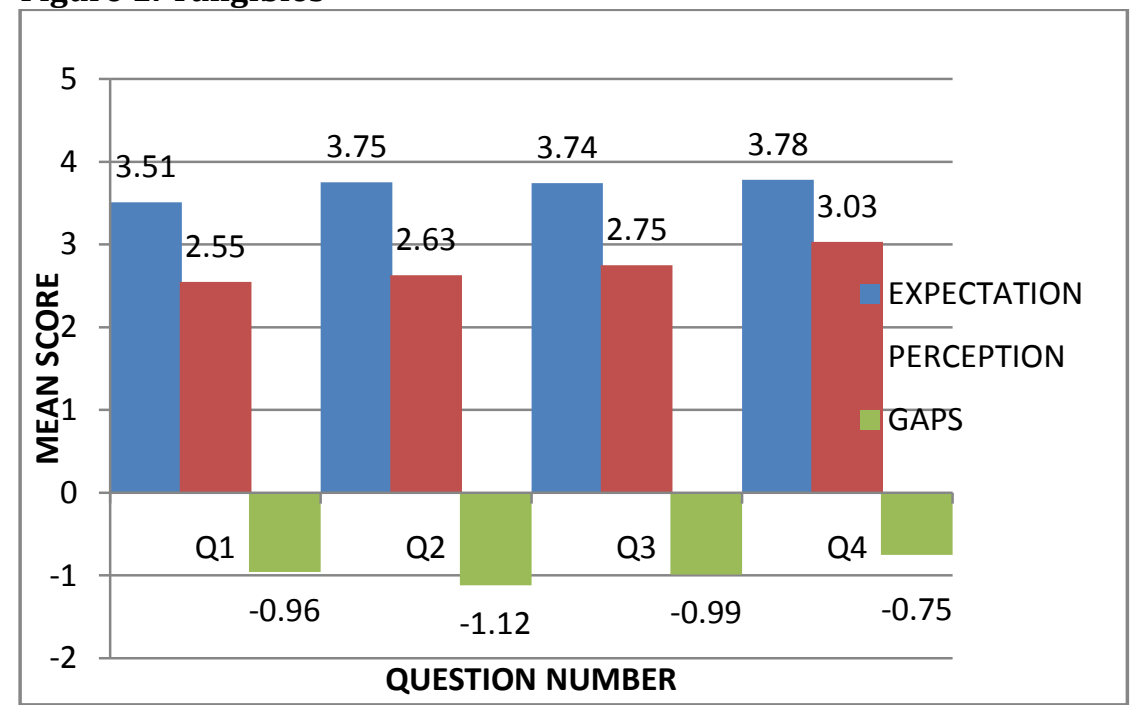

\section{Figure 2: Reliability}

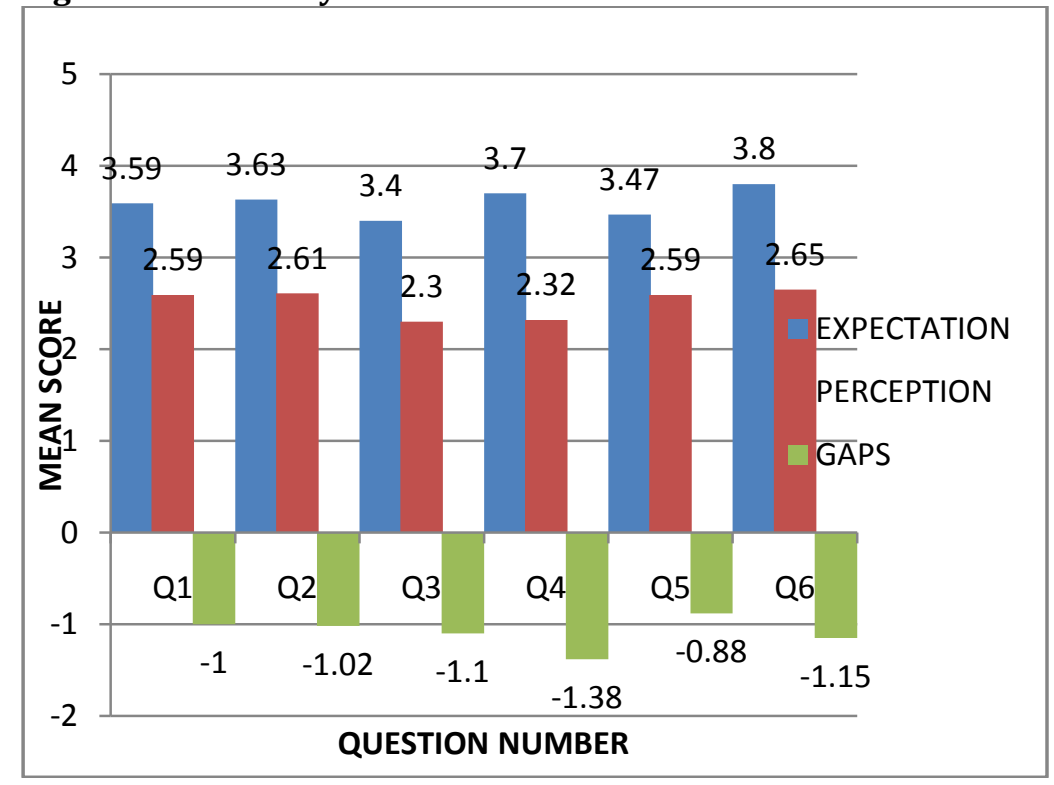

As indicated in Figure 2, the two statements had relatively the same expectation mean score of 3.40 for "staff get things right the first time", while "staff will insist on error-free records" had a mean score of 3.47. The statements which had the high expectation mean scores are: "staff will tell members exactly when services will be performed" and "staff provides their services at the time they promise to do so" (3.70). The statements "staff promises to do something by a certain time" and "staff will insist on errorfree records" had the same mean score of 2.59. The largest mean score of 2.65 was attributed to "staff 
will tell members exactly when services will be performed". It is evident in this group that the gaps scores were high by comparison to the other groups. The highest gap score of 1.38 is attributed to "staff provides their services at the time they promise to do so" and the lowest gap score of 0.88 is for "staff will insist on error-free records". According to Bebko (2001), reliability is a key dimension that customers can use to evaluate the quality between that received and one which the provider promised during the delivery process (e.g. service provision, problem resolution, and pricing). All firms need to be aware of customer expectations of reliability.

Figure 3: Responsiveness

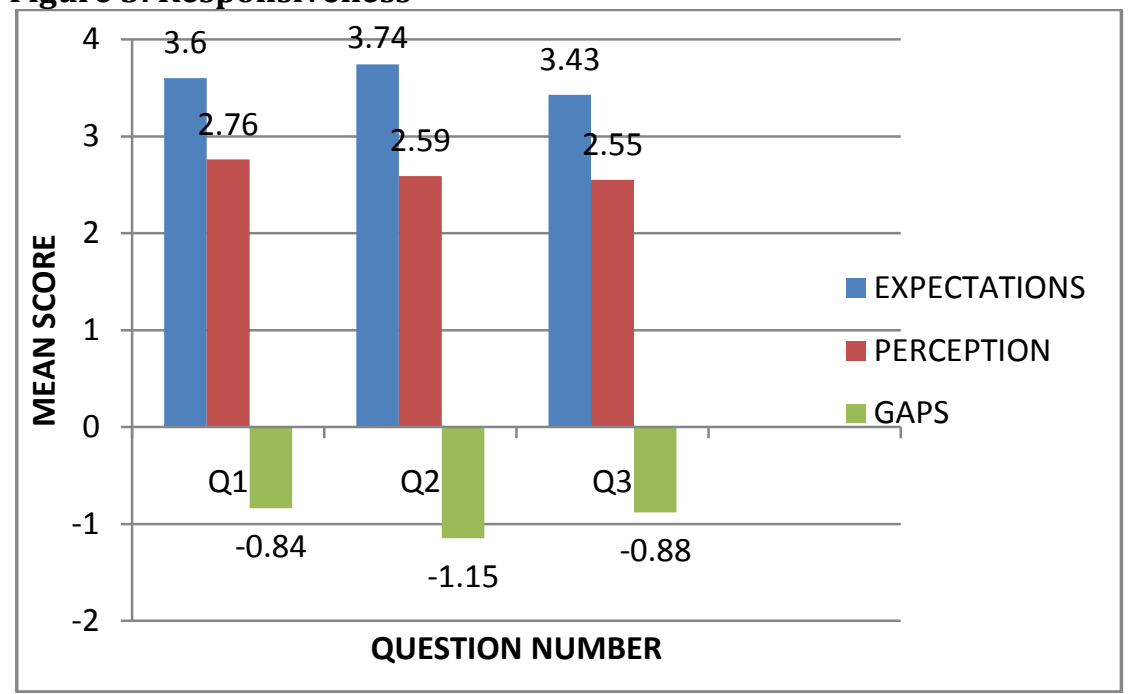

For the statements primarily describing the willingness of the sports department to help members and providing prompt service, as well as the employees' skills and abilities to interact with people, as evidenced in Figure 3, the expectation scores ranged from between 3.43 and 3.74, while the perception scores ranged between 2.55 and 2.76. The largest gap was 1.15 and the lowest gap was 0.84 . The average gap score was 0.95 . It was noted that "staff always willing to help members" had the largest gap amongst all attributes and needs to be investigated for further improvements. Zeithaml et al. (2006) suggest that service providers should be active and volunteer to help their customers and to provide prompt service. This dimension demands that the service provider should be more flexible in solving their customers' problems and requests. Firms should have a capacity to customize services for dealing with their customers' special needs.

Comparison of dimensions: Table 2 indicates that the expectations for the sport offering at the DUT rates tangibles at the highest score of 3.69 , while reliability is 3,60 and responsiveness is 3.59 . For the dimensions relating to perception, reliability is rated very low with a score of 2.50 , responsiveness follows with 2.63 and tangibles has a score of 2.74. The highest gap score of 1.10 was attributed to the reliability dimension. The gap was significantly higher by comparison to the other quality dimensions. The low reliability may not be due to lack of staff competence but inconsistency between what is externally communicated (promised) and what the service delivery system is actually able to provide the customers with. However, the gap scores for the other dimensions namely: tangibles 0.95 and responsiveness 0.96 was also seen to be high.

Table 2: Comparison of dimensions

\begin{tabular}{llll}
\hline Dimension & $\begin{array}{l}\text { Expectation } \\
\text { Mean (SD) }\end{array}$ & $\begin{array}{l}\text { Perception } \\
\text { Mean (SD) }\end{array}$ & $\begin{array}{l}\text { Gap } \\
\text { PM-EM }\end{array}$ \\
\hline Tangibles & $3.69(0.83)$ & $2.74(0.79)$ & -0.95 \\
Reliability & $3.60(0.77)$ & $2.50(0.73)$ & -1.10 \\
Responsiveness & $3.59(0.90)$ & $2.63(0.89)$ & -0.96 \\
\hline
\end{tabular}

\section{Conclusion and Recommendations}

The tangibility dimension is related to the tangibles dimension of the five dimensions of SERVQUAL. Tangibles are used by customers to evaluate the quality of services. Tangibles include a wide variety of 
objects such as carpeting, desks, lighting, wall colors, brochures, daily correspondence and the appearance of the personnel. This study showed that the largest gap in this factor was related to the failure of the physical facilities. This implies that the physical facilities were not appealing and failed to attract students. This might be due to unprofessional management of the tangibility aspects in the sports centre. To close all the 'tangibility' gaps, the following recommendations are made: the facilities should be kept neat with attractive and/or updated equipment, employees should have uniforms because the image of the sports facilities is also reflected by the appearance of their employees and staff should be aware of the importance of maintaining the tangible elements to ensure that students are always attracted to its visual appeal and an enhanced top-of-mind awareness of the DUT sport. The reliability dimension is a combination of the original reliability and credibility dimensions of the SERVQUAL model. Reliability refers to the ability of a service organization to deliver on its promise and to resolve service problems experienced by customers. Reliable managers are able to perform the promised service dependably and accurately. However, this study revealed that the largest gap in this dimension was that students did not receive promised service for their paid membership. This implies that managers failed to perform the promised service dependably and accurately. This could be due to overpromising by sports managers in advertisements, either deliberately or unintentionally. To close all the 'reliability' gaps, the following recommendations are made: staff should understand the importance of keeping promises as well as the danger of overpromising, staff should use different methods to ascertain what students want and then provide it in a way that is consistent with the student's expectations of value and quality, staff should ensure that all the facilities are checked regularly.

The responsiveness dimension is related to the responsiveness dimension of the five dimensions in the SERVQUAL model. Responsiveness refers to the willingness and readiness of employees to deal with customer requests, questions, complaints and problems. Responsive managers are those who make an effort to help guests and provide a prompt response. According to this study, the largest gap in this dimension related to the failure of staff to help students' with their requests for bookings of the sports facilities. This implies that employees were viewed as ineffective service providers and generally failed to respond promptly. This might be due to poor working procedures and/or insufficient supervision by managers. To close all the 'responsiveness' gaps, the following recommendations are made the DUT sport department should establish specific working procedures to help employees understand their job responsibilities and managers' expectations, staff should forge a closer internal worker-relationship. This in essence creates an environment that is conducive to the common interest of students, staff performances should be appraised regularly and any gaps identified should assist them to improve customer service quality.

\section{References}

Armstrong, G. \& Keller, P. (2006). Marketing: An introduction. ( $8^{\text {th }}$ Ed), Upper Saddle River: Prentice-Hall. Bateson, J. E. G. \& Hoffman, K. D. (2011). Services Marketing. (4th ed.), Sydney: South-Western

Bebko, C. P. (2001). Service intangibility and its impact on consumer expectations of service quality. Journal of services marketing, 14(1), 9-26.

Bodet, G. (2006). Investigating Customer Satisfaction in a Health Club Context by an Application of the Tetraclasse Model. European Sport Management Quarterly, 6(2), 149-165.

Cant, M. C., Brink, A. \& Brijball, S. (2002). Customer Behavior - A South African Perspective. Cape Town: Juta.

Curry. A. \& Sinclair, E. (2002). Assessing the quality of physiotherapy services using Servqual. International Journal of Health Care Quality Assurance, 15(5), 197-205.

Curwin, J. \& Slater, R. (2002). Quantitative Methods for business decision. ( $5^{\text {th }}$ Ed.) London: Thomson

Kotler, P. \& Armstrong, G. (2008). Marketing Principals: An Introduction. (12th ed.), Upper Saddle River: Prentice-Hall.

Harris, E. K. (2006). Customer Service: A Practical approach. (3 ${ }^{\text {rd }}$ ed.), New Jersey: Prentice-Hall.

Lagrosen, S. \& Lagrosen, Y. (2007). Exploring Service Quality in the health and fitness industry. Managing Service Quality, 17(1), 41-53.

Leedy, P. D. \& Ormrod, J. E. (2005). Practical research: Planning and design. (8 $8^{\text {th }}$ ed.), Upper Saddle River, NJ. Merrill Prentice-Hall.

Lovelock, C. \& Wirtz, J. (2011). Services Marketing: People, Technology, Strategy. (7th ed.), Boston: Pearson

Melewar, H. \& Akel, A. (2005). Facets of Corporate Identity, Communication and Reputation. Journal of Marketing Management. 16(8), 859 - 916. 
Perez, M. S., Abad, J. C., Carrillo, G. M. \& Fernandez, R. S. (2007). Effects of service quality dimensions on behavioral purchase intentions: A study in public-sector transport. Managing Service Quality, $17(2), 134-151$.

Robledo, M. A. (2001). Measuring and managing service quality: Integrating customer expectations. Managing Service Quality, 11(1), 22-31.

Ryningen, B. (2010). History of sport. [Online]. (Available: http://www.suite101.com/content/sporthistory_[Accessed 2 June 2010].

Sport Union-Home Page. (2006). UKZN [Online]. Available at: http://www.sport.ukzn.ac.za/ [Accessed on 04 April 2011].

Zeithaml, V. A. \& Bitner, M. J. (2000). Services Marketing: Integrating Customer Focus across the Firm. New York: McGraw-Hill.

Zeithaml, V. A., Bitner, M. J. \& Gremler, D. D. (2006). Services Marketing: Integrating Customer Focus across the Firm. (4th ed.), New York: McGraw-Hill 